\title{
Minimization and identification of conducted emission bearing current in variable speed induction motor drives using PWM inverter
}

\author{
${ }^{1}$ A RAMACHANDRAN, ${ }^{1}$ M CHANNA REDDY and ${ }^{2}$ RANJAN \\ MOODITHAYA
}

${ }^{1}$ Vemana Institute of Technology, Bangalore 560034

${ }^{2}$ National Aerospace Laboratories, Bangalore 560017

*e-mail: arama1947@yahoo.co.in

\begin{abstract}
The recent increase in the use of speed control of ac induction motor for variable speed drive using pulse width modulation (PWM) inverter is due to the advent of modern power electronic devices and introduction of microprocessors. There are many advantages of using ac induction motor for speed control applications in process and aerospace industries, but due to fast switching of the modern power electronic devices, the parasitic coupling produces undesirable effects. The undesirable effects include radiated and conducted electromagnetic interference (EMI) which adversely affect nearby computers, electronic/electrical instruments and give rise to the flow of bearing current in the induction motor. Due to the flow of bearing current in the induction motor, electrical discharge machining takes place in the inner race of the bearing which reduces the life of the bearing. In high power converters and inverters, the conducted and radiated emissions become a major concern. In this paper, identification of bearing current due to conducted emission, the measurement of bearing current in a modified induction motor and to minimize the bearing current are discussed. The standard current probe, the standard line impedance stabilization network (LISN)), the electronics interface circuits are used to measure high frequency common mode current, bearing current and to minimize the conducted noise from the system. The LISN will prevent the EMI noise entering the system from the supply source by conductive methods, at the same time prevents the EMI generated if any due to PWM, fast switching in the system, will not be allowed to enter the supply line. For comparing the results with Federal Communications Commission (FCC) and Special Committee on Radio Interference (CISPR) standards, the graphs are plotted with frequency Vs, line voltage in $\mathrm{dB} \mu \mathrm{V}$, common mode voltage in $\mathrm{dB} \mu \mathrm{V}$ and the bearing current in $\mathrm{dB} \mu$ A with out and with minimizing circuits.
\end{abstract}

Keywords. EMI; a.c. drives; bearing current.

\footnotetext{
*For correspondence
} 


\section{Introduction}

With the development of power electronic devices like the insulated gate bi-polar transistor (IGBT), the power MOSFET and the advances in microprocessors, the ac induction motor is becoming popular in variable speed drives with PWM inverter circuits. Since the rise time and fall time of the IGBT's are less than 200 nano-seconds, the dissipation loss across the device becomes very less and there by increases the performance of the circuit. However, due to the fast switching action of the device the $\mathrm{dv} / \mathrm{dt}$ of the inverter output becomes large. This high $\mathrm{dv} / \mathrm{dt}$ voltage transition coupled with parasitic stray capacitance in the system causes high frequency line to ground current or common mode current and hence bearing current; introducing large EMI in the system.

In figure $1, I_{l g}$ the magnitude of ground current depends on the cable capacitance, machine capacitance, parasitic capacitance of the devices, the output voltage rise time $\left(t_{\text {rise }}\right)$ and the system voltage. Voltage gets induced in the rotor shaft of the induction motor due to fast switching. This induced voltage generates circulating current and flows to the ground through the bearing resulting in an electrical discharge machining (EDM) action at the inner race of the bearing (Shaotang Chen 1995).

Due to the EDM, the life of the bearing reduces. The common mode voltage $V_{n g}$ (figure 1) can be measured from the star point of the stator winding of the induction motor (IM) or connected node of three $1 \mathrm{M} \Omega$ resistors to the ground in case of the IM connected in delta. The reasons for common mode voltage generation are already discussed (Gary Skibinski et al 1999; Han-Jong Kim et al 2001).

It is noted that the sum of sinusoidal balanced phase voltages in a 3-phase I.M. at the star point is equal to zero. Therefore,

$$
\begin{aligned}
& V_{n g}=\left(V_{a n}+V_{b n}+V_{c n}\right) / 3 \\
& \text { Common mode current }=C d v / d t .
\end{aligned}
$$

Where ' $\mathrm{C}$ ' is the total capacitance of the system and $V_{a n}, V_{b n}$ and $V_{c n}$ are the voltages between the respective phases and the star point in the stator winding.

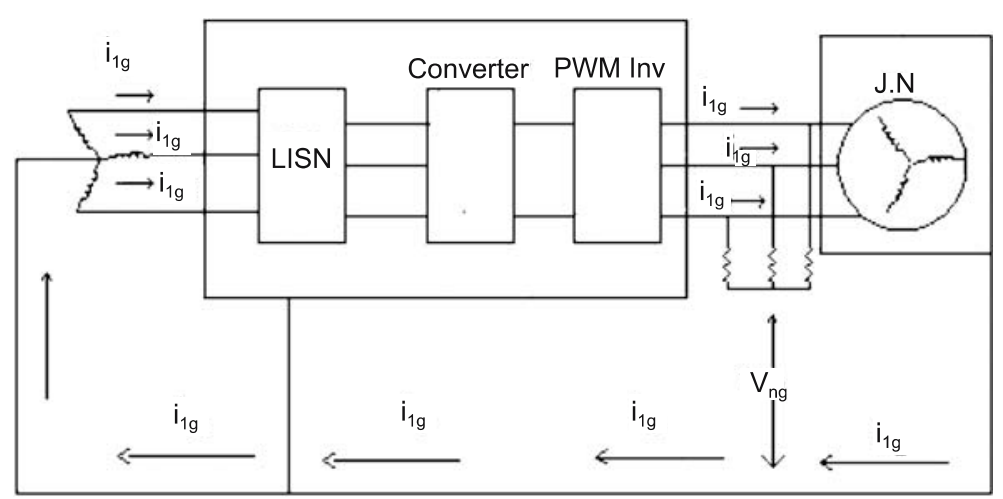

Figure 1. Schematic diagram of the drive system. 


\section{Existing conducted emission, bearing current identification and measurement methods}

Various methods have been proposed to reduce the conducted emission common mode voltage and the measurement of bearing current (Shaotang Chen 1995; Melfi et al 1997; Finlayson 1998). An output reactor connected to the inverter out put reduces the $\mathrm{dv} / \mathrm{dt}$ of the inverter output voltage, which in turn reduces the common mode voltage at the star point of the IM and the flow of bearing current. Various configurations of L-C filter have been reported (Laszlo Tihanyi 1995). The inductance ' $L$ ' and capacitance ' $C$ ' are designed according to the permitted insertion loss for the given power rating of the inverter. The draw back of the filter method is the voltage drop across the filter.

In the passive filter method (David Hyypio 2005), the transformer secondary should be isolated for its successful operation and this is not possible in many process/engineering industries. An active common-noise canceller has been tried (Ogasawara et al 1998; Mahesh Mysore Swamy et al 2001) to eliminate the conducted emission common mode voltage produced by the PWM inverter. The active common noise canceller superimposes a compensating voltage applied at the star point. This has the same amplitude as the common mode voltage produced by the PWM inverter but has opposite polarity; hence the common mode voltage applied to the load is cancelled completely. However, this method is suitable only for low voltage/power applications due to the resistive current sensor.

Yo-Chan Son \& Seung-Ki Sul (2002); Julian et al (1998) proposed a filter circuit for reducing the common mode voltage. This filter circuit is based on current sensing and it operates a fast transistor amplifier for the current compensation. Significant attenuation of the common mode voltage occurs.

The method presented in this paper is different from earlier methods. Here, the phase current is sensed by the individual current transformer (CT) and is suitable for any voltage level. Since the CT is used for sensing the phase current there is no voltage drop in the sensor there by there is no reduction of terminal voltage applied to the IM.

In Yo-Chan Son \& Seung-Ki Sul (2002); circuit the primary winding of the transformer is connected in series in each of the phases. Since the circuit uses the transformer there is voltage drop due to the phase current of the IM, hence the terminal voltage applied to the IM gets reduced. Yo-Chan Son \& Seung-Ki Sul (2002) circuit is also used to reduce the common mode voltage and the common mode current at the star point of the IM. But this circuit is useful for the low voltage and low power applications.

In the present work, the standard LISN, the standard current probes are used and the results are compared without and with the common mode voltage reduction circuits for the PWM inverter used for variable speed ac IM drives.

\subsection{Working of the circuit}

The block diagram of the drive and conducted emission common mode voltage minimizing circuit is shown in figure 2 . The conducted emission common mode voltage minimizing circuit block diagram is shown in figure 3 . The system works on the principle of sensing the individual phase currents using CTs with a suitable ratio. A resistor shorts the secondary of the CT. The voltage across the resistors are individually amplified and summed. The summed output is further amplified using high precision, wide band and high CMRR amplifier (make: Preston company, USA). The output of the amplifier is fed to the PNP and NPN transistor's bases to amplify the negative and positive side signals separately. The negative and positive amplified voltages are fed to the two opto-isolator circuits separately. The opto-isolator outputs are 


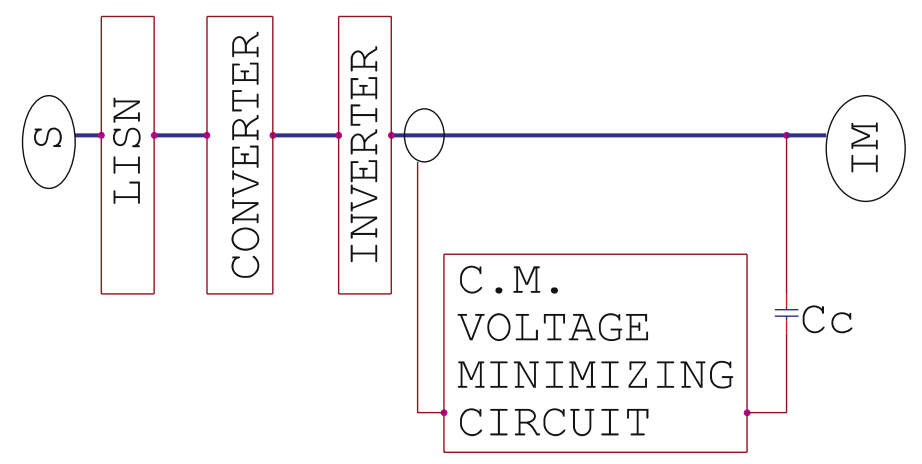

Figure 2. Block diagram of drive and control circuit for minimizing of conducted emission common mode voltage.

amplified by the high frequency transistors and fed to the gate of corresponding IGBT. The opto-isolator circuit is used to isolate the power circuit from the rest of the control circuit.

In the push-pull amplifier, the IGBTs (the IGBTs are used in the switch mode and not in the amplifier mode) are used as the switching devices. The IGBTs are switched ON and OFF as per the CT secondary sensed and amplified voltage in the block diagram in figure 3. When the IGBTs are ON, all the high frequency voltages take the shortest path to the ground through the capacitor $C_{c}$, whereas for the low frequency supply, the capacitor $C_{c}$ offers high impedance. In figure 3 , the coupling capacitors $C_{c}$ are connected to the inverter output lines.

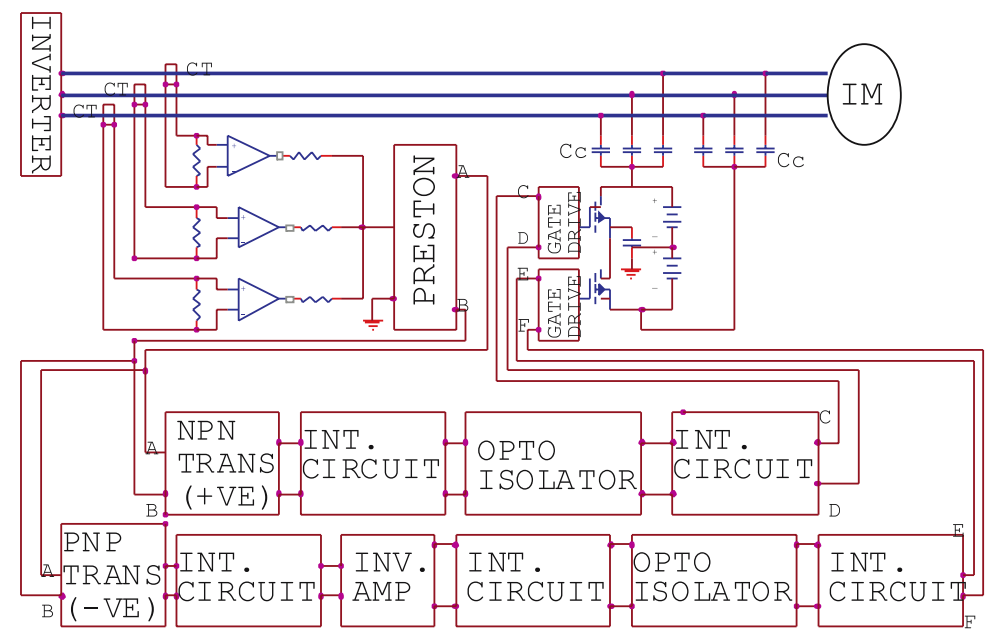

Note: $-\mathrm{CT}=$ current transformer. $\mathrm{Cc}=$ coupling capacitor. PRESTON $=$ High CMRR diff. $\mathrm{i} / \mathrm{p}$ amplifier (manufactured by M/s Preston Inc, USA). GATE DRIVE = gate drive circuit for IGBT. NPN TRANS $(+\mathrm{ve})=$ npn transistor for amplifying the +ve signals. PNP TRANS $(-\mathrm{ve})=$ pnp transistor for amplifying the - ve signals. INT. CIRCUIT $=$ interface circuit. INV. AMP = Inverting amplifier. OPTO ISOLATOR = opto-isolator chip (6N139).

Figure 3. Block diagram of control circuit for minimizing conducted emission common mode voltage. 


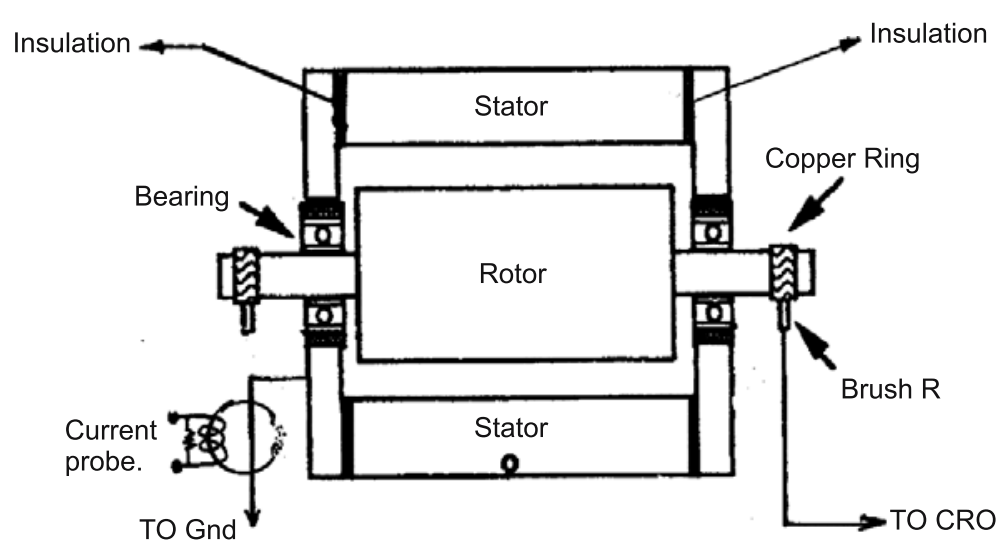

Figure 4. Modified induction motor for measurement of bearing current.

The coupling capacitors $C_{c}$ are chosen such that their impedance is sufficiently low at EMI noise frequency. In this method, all high frequency noise voltages are filtered from the inverter output voltage. In the circuit shown in figure 3, the high frequency noise voltages at the star point of the induction motor are reduced but the carrier frequency and the envelop of the fundamental frequency voltage are not reduced at the star point of the induction motor. This has to be reduced by injecting an appropriate signal at the star point of the induction motor, which is not discussed in this paper. Since the high frequency voltages are not allowed to the IM, the common mode high frequency voltages are not present at the terminal of the IM hence the high frequency bearing current is also low.

\section{Bearing current measurement}

The modified induction motor is shown in figure 4. The end plates of the IM are machined and insulated in such way that the main body and the end plates are electrically isolated. Therefore the induced voltage and the capacitive coupling voltage in the shaft do not get grounded through the main body of the induction motor. But it will be grounded from the rotor through the bearing. The current through the bearing from the shaft to the ground is measured using a current probe. A digital storage oscilloscope as shown in figure 4 measures the shaft voltage. The bearing current is measured without minimization circuit for the common mode voltage and also with minimization circuit. The graphs show the differences.

After insulating the end plates from the main body there may be capacitive coupling from both the ends of the stator winding to both the end plates; but this coupling will be minimum, since the air-gap from the end of the winding of the stator to the end plates are comparatively larger. Hence it is assumed that there is no coupling current. Therefore the shaft induced voltage produces rotor current and will flow through the bearing to the ground via the end plate, hence that current is called bearing current. In addition, both sides end plates are isolated hence there is no chance of circulating current between them. Based on the above reasoning there will not be much difference in common mode voltage by insulating the end plates.

The theory of 'shaft voltage and bearing current' was discussed, (Alexander Julion 1997) in a detailed manner and similarly the papers on 'bearing current and the relationship to PWM drives' and 'A solution to Rotor Shaft Voltage Buildup and Bearing current' was discussed (Doyle Busse et al 1995, 1996). 


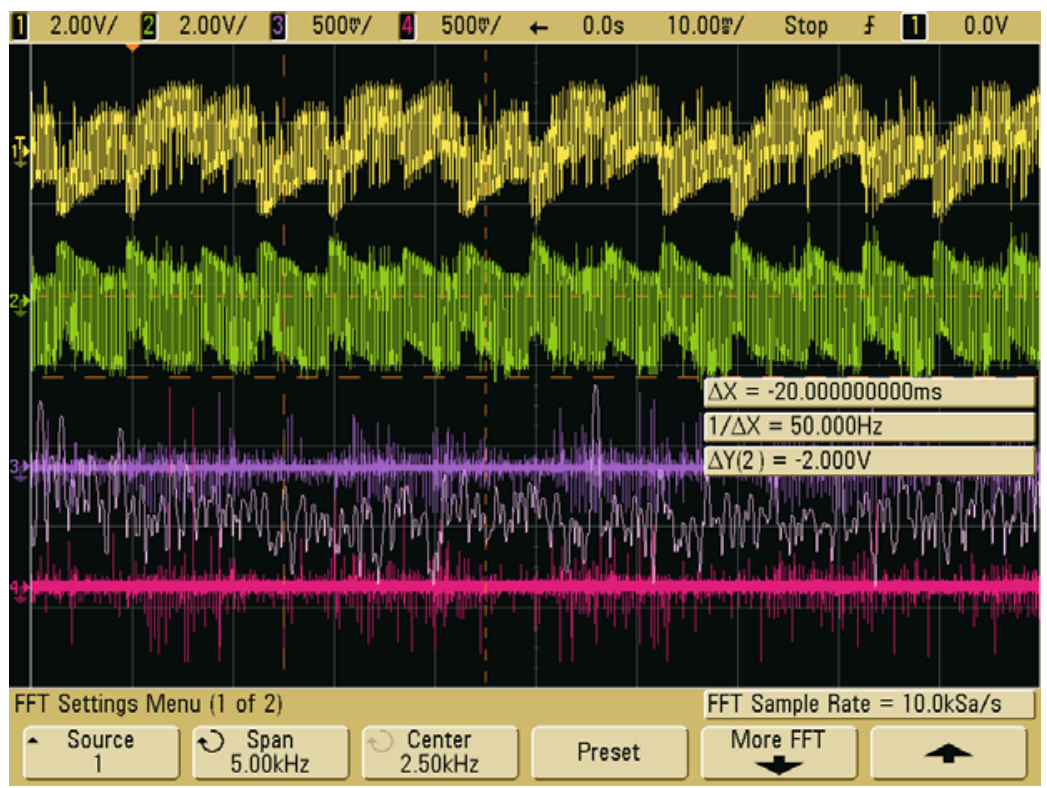

Figure 5a. Waveform without minimizing control circuit. Ch.1. (200:1) Star point (cap) and gnd. voltage. Ch.2.(200:1) Line voltage applied to IM. Ch.3. Vector sum of phase current (current probe output in volts). Ch.4. Bearing current (current probe output in volts).

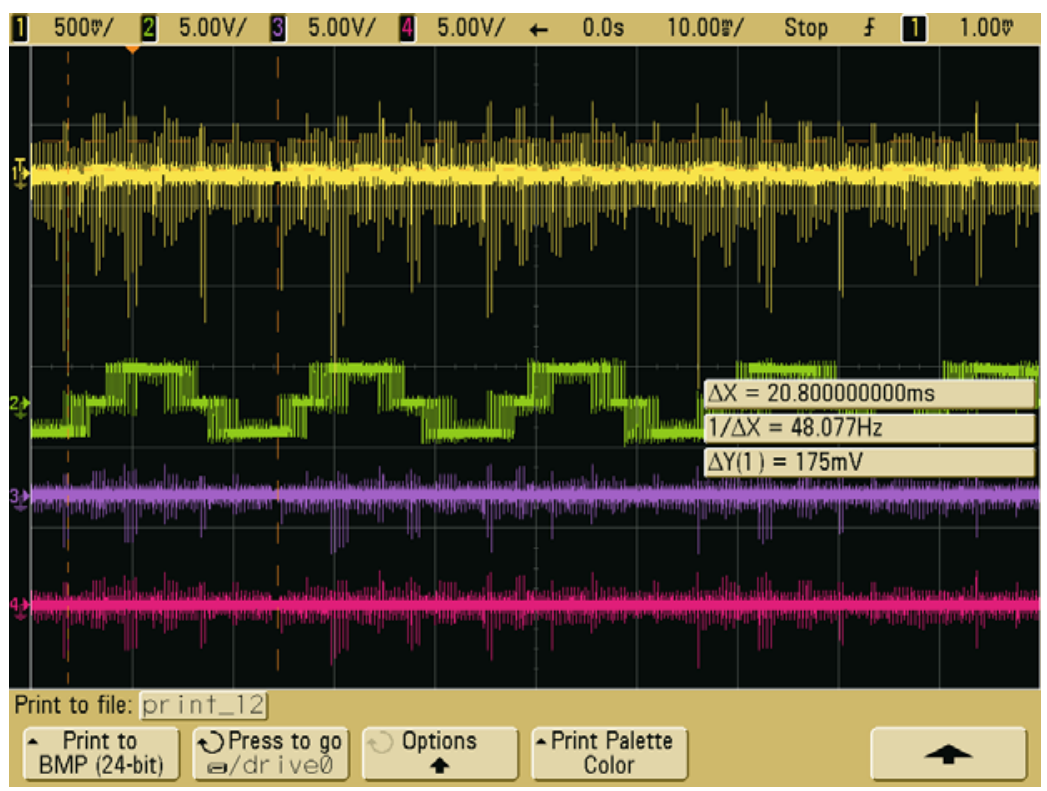

Figure 5b. Waveform with minimizing control circuit. Ch.1: (20:1) Star point and ground voltage. Ch. 2:(200:1) line voltage (IM). Ch.3: Vector sum of phase current (current probe output in volts) Ch.4: C.M. Current (current probe output in volts). 

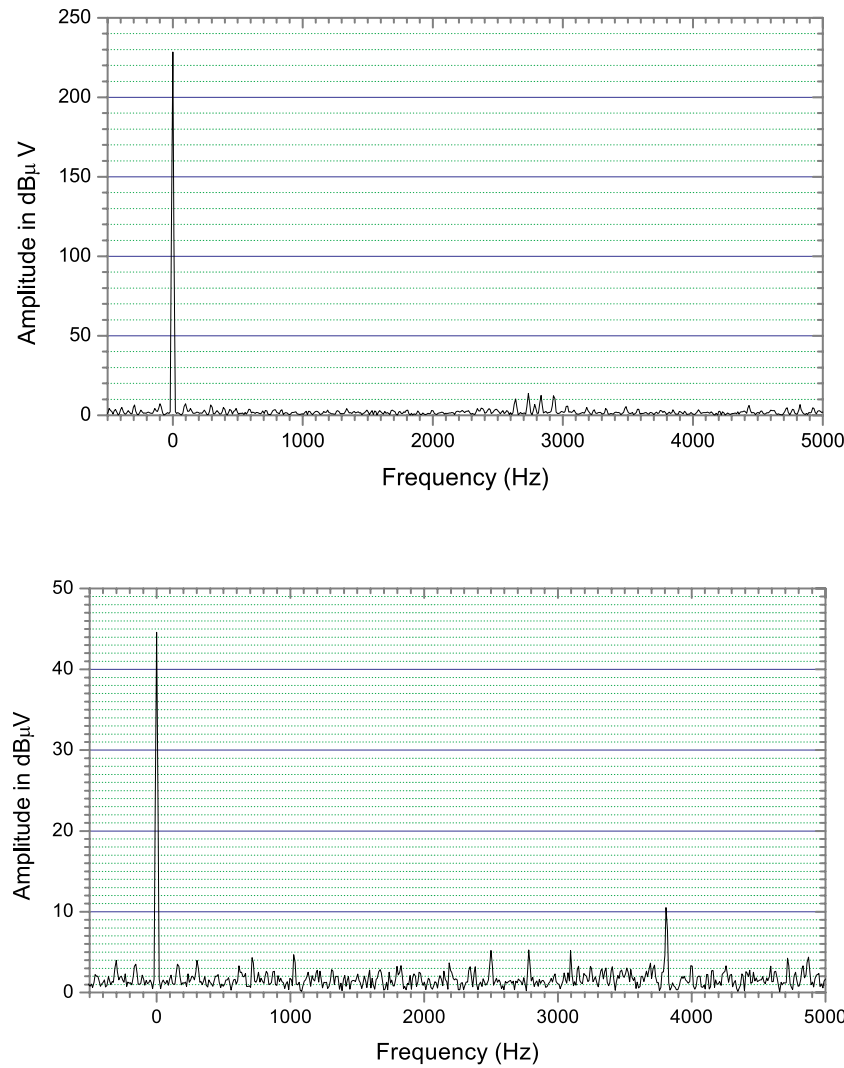

Figure 6a. FFT waveform of star point and ground voltage up to $5000 \mathrm{~Hz}$ (without minimizing circuit).

Figure 6b. FFT of Star point and ground voltage up to $5000 \mathrm{~Hz}$ (with minimizing circuit).

\section{Experimental results}

The system shown in figure 3 was implemented on $400 \mathrm{~V}, 3$-phase ac induction motor drive system with a PWM of $2.5 \mathrm{kHz}$ switching carrier frequency. The circuit reduces the common mode high frequency voltages and the common mode current to the limit accepted to FCC/CISPR standards. The IM line voltage, common mode voltage, vector sum of phase current and bearing current without minimizing circuit are shown in the figure 5a. In figure 5a,

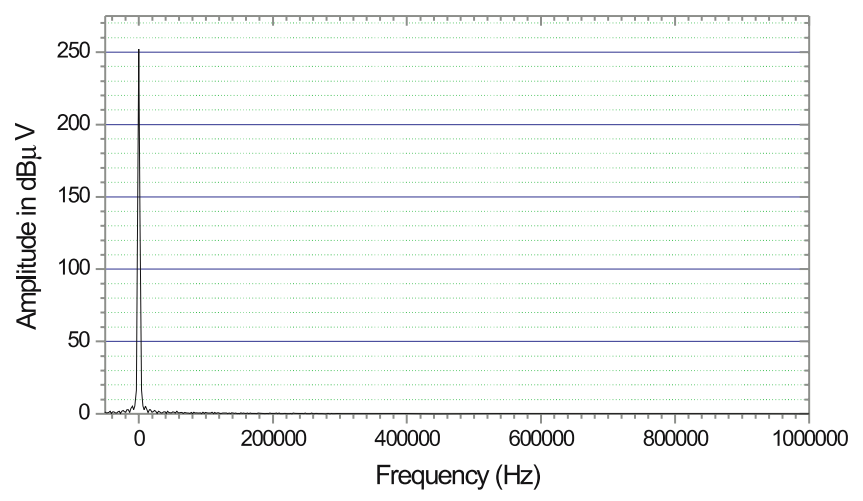

Figure 7a. FFT waveform of star point and ground voltage up to $1 \mathrm{MHz}$ (without minimizing circuit). 

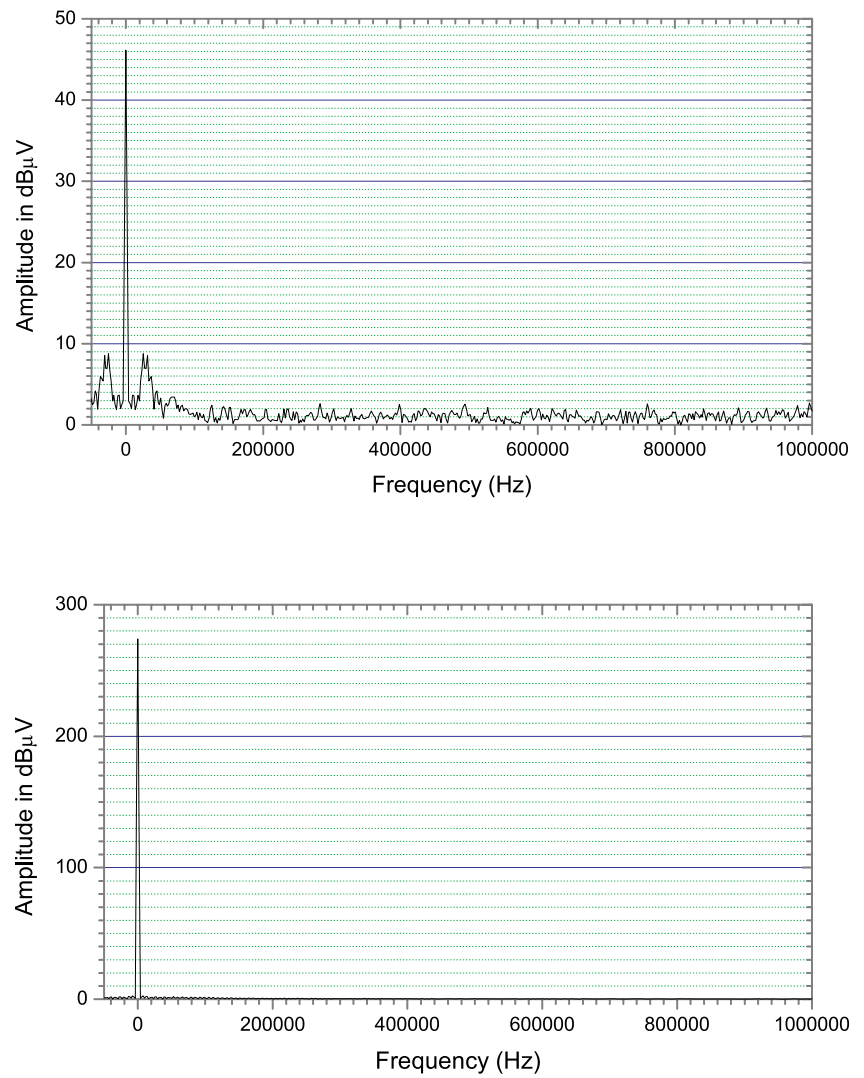

Figure 7b. FFT of Star point and ground voltage up to $1 \mathrm{MHz}$ (with minimization circuit).

Figure 8a. FFT waveform line voltage up to $1 \mathrm{MHz}$ (without minimization circuit).

the channel-2, reads the line voltage. The waveform looks that it is curved and distorted. The reason is that the capacitor at the output of the converter bridge is not enough to smoothen it. Refer the figure $5 \mathrm{~b}$, for the line voltage of the stator winding with mitigation.

The common mode current is passed to the ground through standard current probe and the common mode current is computed using the current probe secondary voltage.

$$
I_{P}=\left(E_{S} / Z_{T}\right) \text {. }
$$

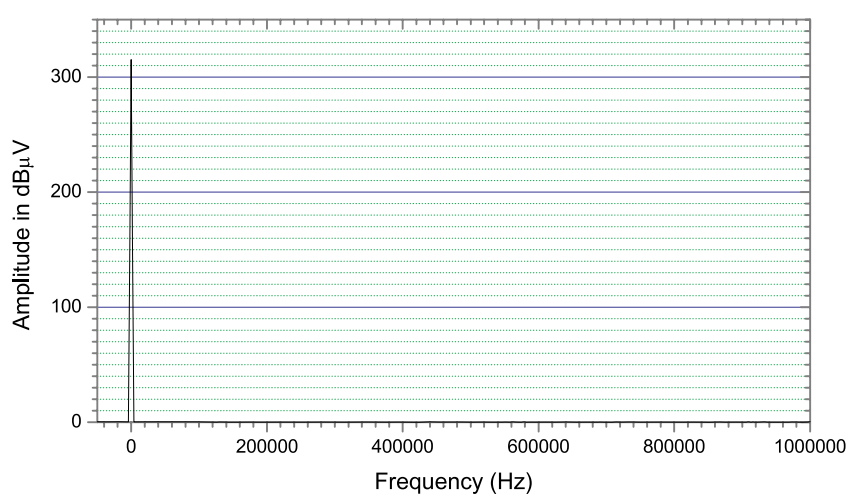

Figure 8b. FFT of line voltage applied to IM up to $1 \mathrm{MHz}$ (with minimization circuit). 

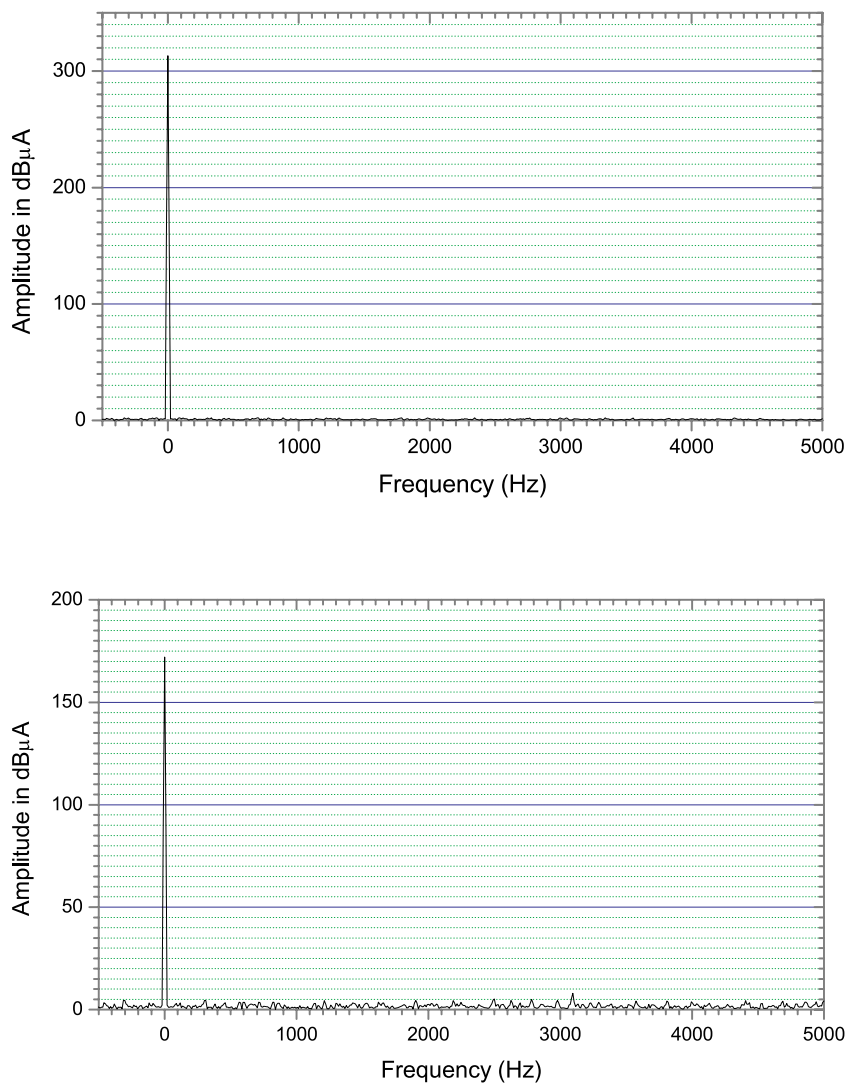

Figure 9a. FFT of vector sum of phase current (current probe output in volts) up to $5000 \mathrm{~Hz}$ (without minimizing circuit).

Figure 9b. FFT of vector sum of phase current (current probe output in volts) up to $5000 \mathrm{~Hz}$ (with minimizing circuit).

Where, $I_{P}=$ unknown primary current, $E_{S}=$ measured EMI volts. $Z_{T}=$ transfer impedance $(2 \Omega)$.

The IM line voltage, common mode voltage, vector sum of phase current and bearing current without minimizing circuit are shown in figure 5a. The IM line voltage, common mode voltage, vector sum of phase current and the common mode current with minimizing

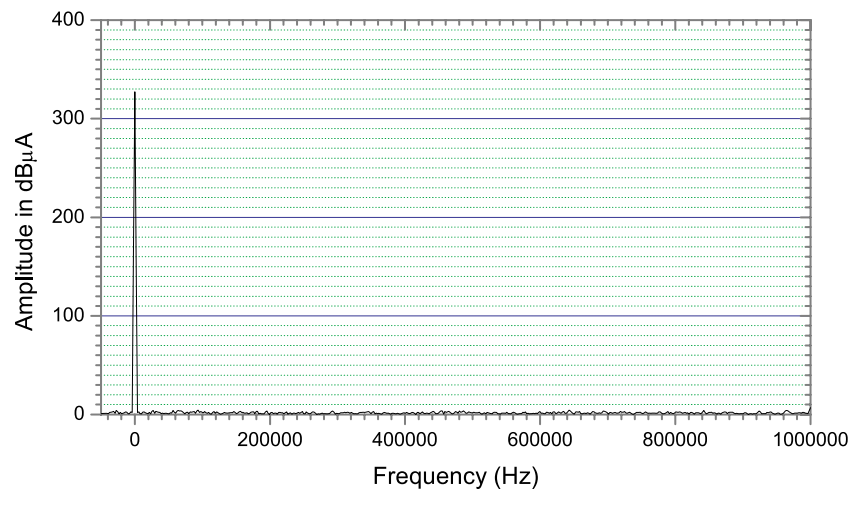

Figure 10a. FFT of vector sum of phase current (current probe out put in volts) up to $1 \mathrm{MHz}$ (without minimizing circuit). 

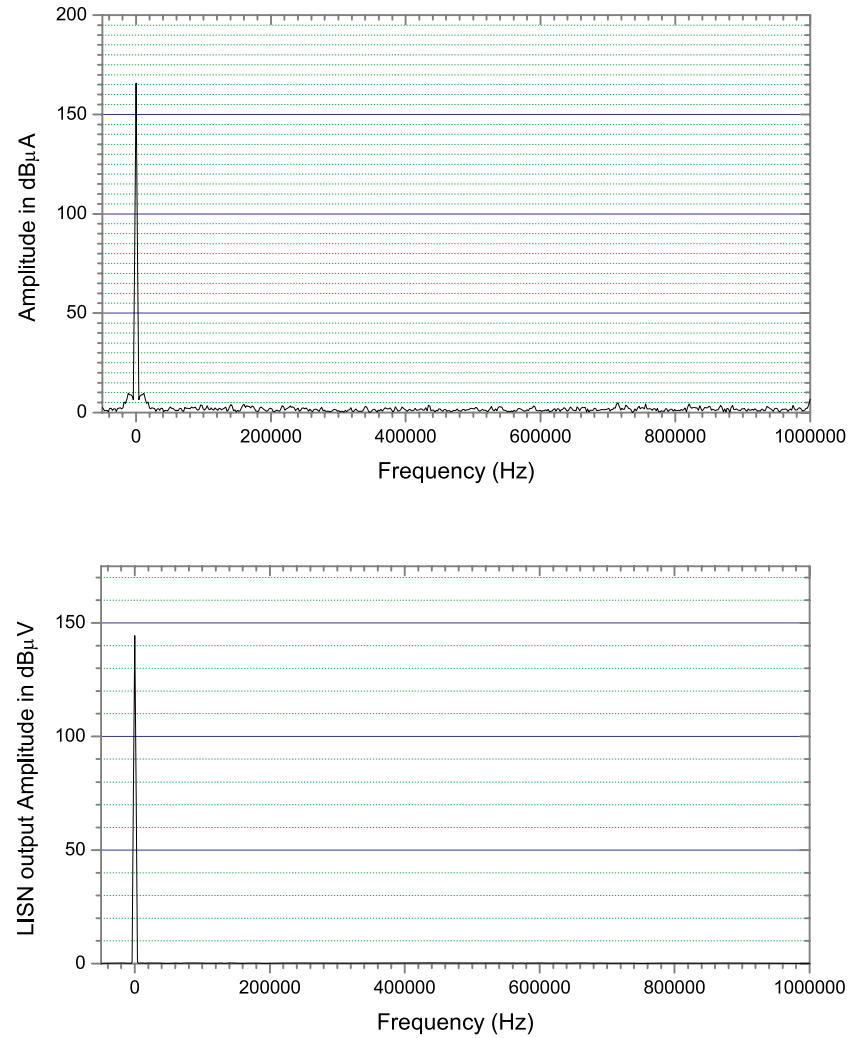

Figure 10b. FFT of vector sum of phase current (current probe output in volts) up to $1 \mathrm{MHz}$ (with minimization circuit).

Figure 11a. FFT of LISN output voltage up to $1 \mathrm{MHz}$ (without minimizing circuit).

circuit are shown in the figure $5 \mathrm{~b}$. The graphs of $\mathrm{dB} \mu \mathrm{V} / \mathrm{dB} \mu \mathrm{A}$ against frequency for various parameters are shown in figures $6 \mathrm{a}-15$.

\section{FFT results}

Figures $6 \mathrm{a}-7 \mathrm{~b}$ show the FFT graph of star point to ground voltage in $\mathrm{dB} \mu \mathrm{V}$ against frequency of the inverter without and with minimizing control circuit. Figures $8 \mathrm{a}$ and $8 \mathrm{~b}$ show the FFT

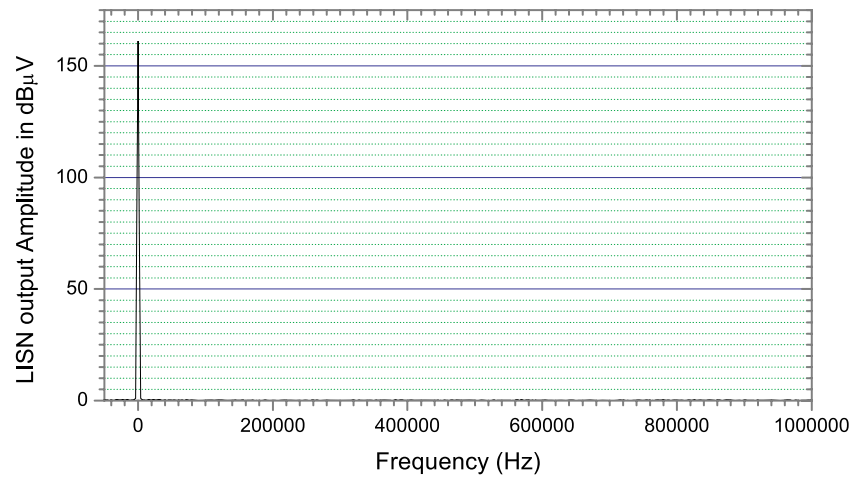

Figure 11b. FFT of LISN output voltage up to $1 \mathrm{MHz}$ (with minimizing circuit). 

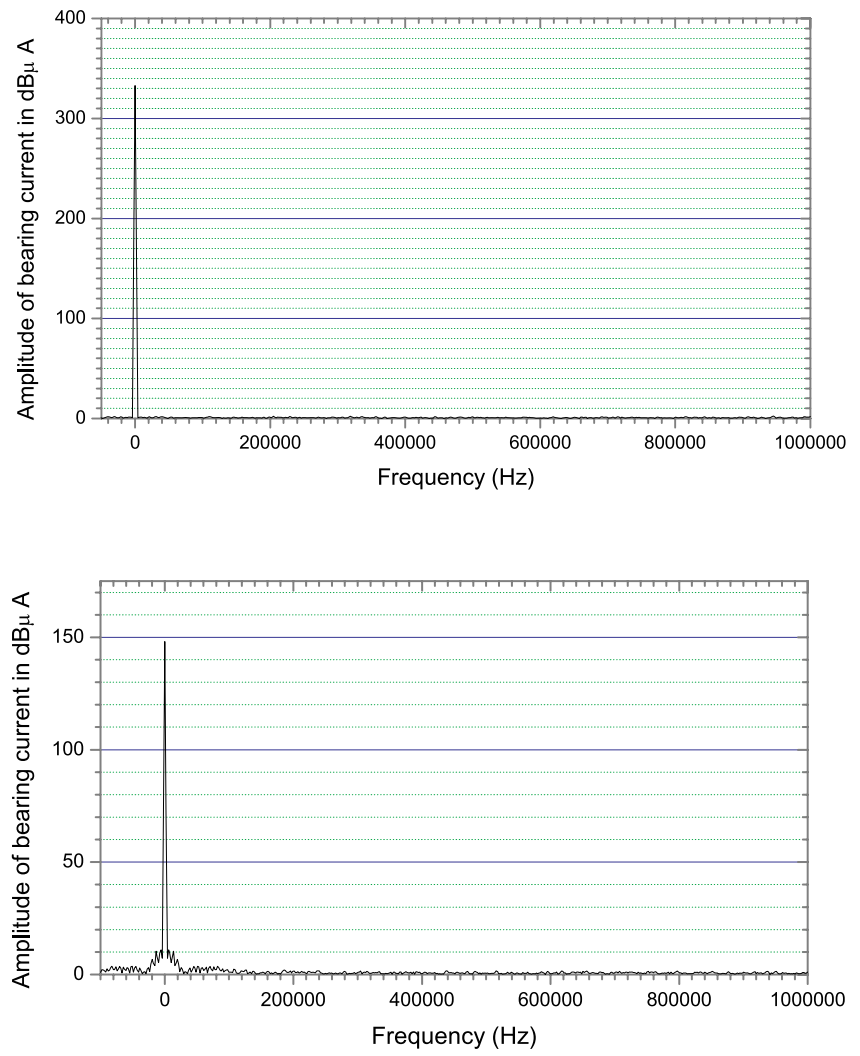

Figure 12a. FFT of bearing current (current probe output) up to $1 \mathrm{MHz}$ (without minimizing circuit).
Figure 12b. FFT of bearing current. (current probe output) up to $1 \mathrm{MHz}$ (with minimizing circuit).

graph of line voltage in $\mathrm{dB} \mu \mathrm{V}$ against frequency of the inverter out put voltage applied to the induction motor without and with minimizing control circuit. Figures $9 a-10 b$ show the FFT graph of vector sum of three phase currents of the induction motor in $\mathrm{dB} \mu$ A against frequency, without and with minimizing control circuit. Figures $11 \mathrm{a}$ and $\mathrm{b}$ show the FFT graph of LISN out put voltage in $\mathrm{dB} \mu \mathrm{V}$ against frequency, without and with minimizing control circuit. Figures 12a and $\mathrm{b}$ show the FFT graph of the bearing current in $\mathrm{dB} \mu \mathrm{A}$ against

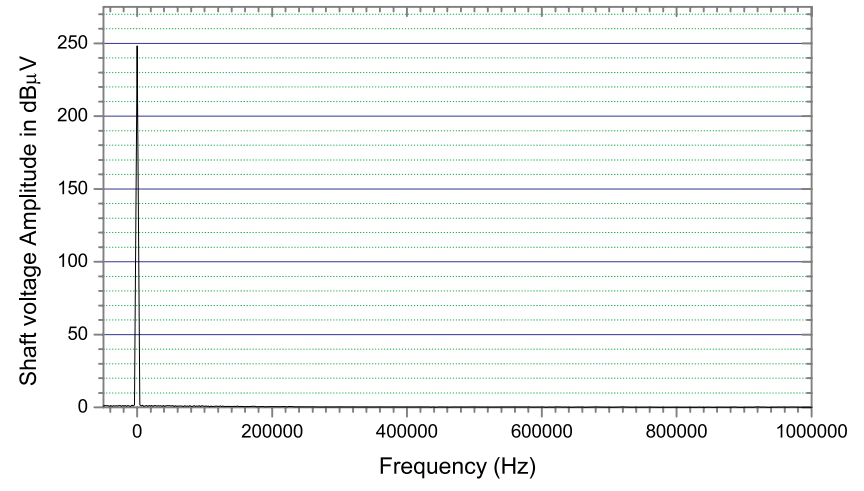

Figure 13a. FFT of shaft voltage (IM) up to $1 \mathrm{MHz}$ (without minimizing circuit). 


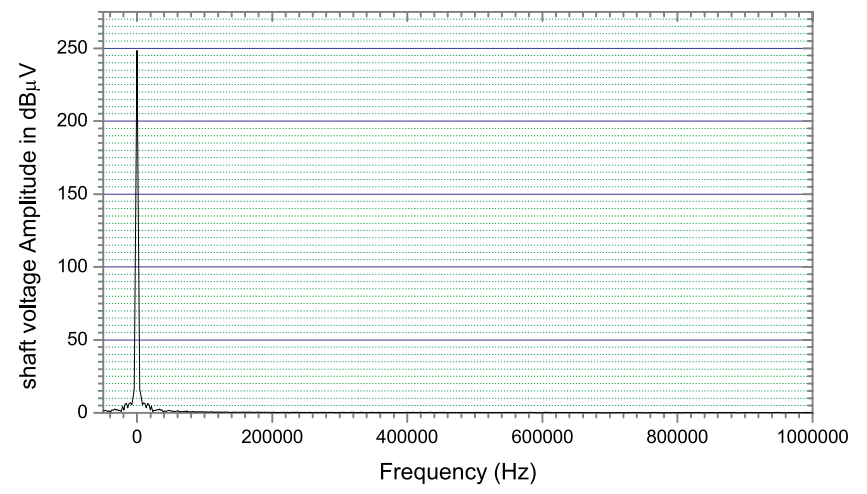

Figure 13b. FFT shaft voltage (IM) up to $1 \mathrm{MHz}$ (with minimizing circuit).

frequency without and with minimizing control circuit. Figures 13a and b show the FFT graph of induction motor shaft induced voltage in $\mathrm{dB} \mu \mathrm{V}$ against frequency, without and with minimizing control circuit. Figures 14-15 show the FFT of common mode current flowing from the star point in $\mathrm{dB} \mu \mathrm{A}$ against frequency with minimizing control circuit.

It is observed that the vector sum of three phase currents and the common mode current are the same in magnitude and phase,

$$
\text { i.e. } I_{a}+i_{b}+i_{c}=0 \text {. }
$$

\section{Concluding remarks}

The peak values of common mode voltage were reduced from $\sim 250 \mathrm{~V}$ to $4 \mathrm{~V}$ by above method. As per the FCC regulations (Paul 1992) for digital devices \{Class 'A' $\}$ it is $60 \mathrm{~dB} \mu \mathrm{V}$ $(0.45-1.705 \mathrm{MHz})$. With common mode voltage reduction control circuit, it is $45 \mathrm{~dB} \mu \mathrm{V}$ and is well within the limits of FCC. It is to be noted that it is also well within the range of CISPR (Paul 1992). The high frequency bearing current was reduced with minimization control circuit. This paper presented the practical system of minimizing the common mode voltage due to PWM inverter using IGBT/power MOSFET and the measurement of bearing current for the variable speed three-phase induction motor drive. The common mode current

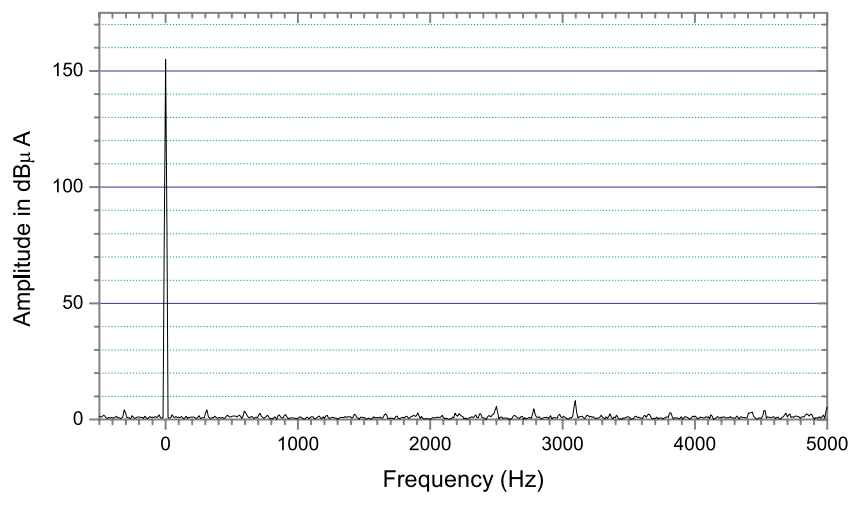

Figure 14. FFT of CM current (current probe output) up to $5000 \mathrm{~Hz}$ (with minimizing circuit). 


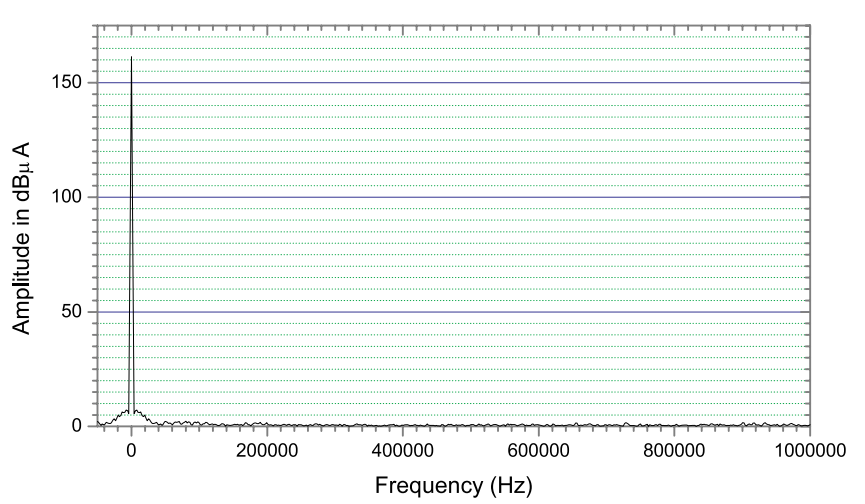

Figure 15. FFT of CM current (current probe output) up to $1 \mathrm{MHz}$ (with minimizing circuit).

in the system was filtered using the minimizing control circuit. The name plate detail of the induction motor used is also given here. Induction Motor make and details: Kirloskar Electric Company. $V_{L}=400 \mathrm{~V}$, Horsepower $=0.37 \mathrm{~kW}, \mathrm{RPM}=1380, I_{L}=1.02 \mathrm{Amps}, \eta=78 \%$.

The authors would like to thank the Director, National Aerospace Laboratories (NAL), Bangalore and Dr J J Isaac, Head Propulsion Division, NAL for permitting and providing all infrastructures for doing the experimental work. We would also like to thank Prof. V Keshava Murthy, University Visveswaraiah College of Engineering (UVCE), Bangalore for the encouragements. We thank Mrs Rajeswari Natarajan, Tech. Officer, Propulsion Division, NAL for the help in conducting the experiments, Mr Janakirami Reddy, Scientist, Propulsion Division, NAL for drawing block diagrams and the Propulsion workshop staff for giving assistance in mechanical fabrication of the system. The authors are thankful to the Principal and management of the Vemana Institute of Technology, Bangalore, for permitting their staff members to publish the paper in this special issue.

\section{References}

Alexander L Julian 1997 Active common mode voltage reduction in voltage source inverters. Ph.D Thesis submitted to Graduate School, University of Wisconsin-Madison, USA

Doyle Busse, Jay Erdman, Russel J Kerkman, Dave Schlegel, Gary Skibinski 1995 Bearing currents and their relationship to PWM drives. IEEE IECON Conference. Orlando, FL. November (Allen Bradley, drives division). 6400 W, Enterprise Drive. Mequon, WI

Doyle Busse, Jay Erdman, Russel J Kerkman, Dave Schlegel, Gary Skibinski 1996 An evaluation of electrostatic shielded induction motor: A solution to rotor shaft voltage buildup and bearing current. IEEE IAS Conference San Diego, CA October, Rockwell Automation, Allen Bradley, 6400 W, Enterprise Drive. Mequon, WI

David Hyypio 2005 Mitigation of bearing electro-erosion of inverter-fed motors through passive common-mode voltage suppression. IEEE Transactions on Industry 41(2):

Finlayson P T 1998 Out put filters for PWM drives with induction motors. IEEE Ind. Applicant. Mag. 4: $45-52$

Gary L Skibinski, Russel J Kerkman, Dave Schlegel 1999 EMI emissions of modern PWM AC drives. IEEE Industrial Applications Magazine 5(6): 47-81

Han-Jong Kim, Geun-Ho Lee, Cheol-Ho Jang, Jea-Pil Lee 2001 Cost effective design of an inverter output reactor in ASD applications. IEEE Transactions on Industrial Electronics 48(6): 
Julian A L, Cuzner R, Oiti G, Lipo T A 1998 Active filtering for common mode conducted EMI reduction in voltage source inverters. IEEE Applied Power Electronics Conference, Anaheim, CA, 934-939

Laszlo Tihanyi 1995 Electromagnetic compatibility in power electronics. (NY: IEEE Press)

Mahesh Mysore Swamy, Kenji Yamada, Tsuneo (jeo) 2001 Common mode current attenuation techniques for use with PWM drives. IEEE Transaction on Power Electronics 16(2)

Melfi M, Sung J, Bell S, Skibinski G 1997 Effect of surge voltage rise time on the insulation of low voltage machines fed by PWM converters. Conf. Rec. IEEE - IAS Annual. Meeting 239-246

Ogasawara S, Ayano H, Akagi H 1998 An active circuit for cancellation of common mode voltage generated by a PWM inverter. IEEE. Trans. On PE 13(5): 835-841

Paul C R 1992 Introduction to electromagnetic compatibility. Wiley Series in Microwave and Optical Engineering, USA: John Wiley \& Sons, Inc.

Shaotang Chen 1995 Bearing current, EMI soft switching in induction motor drives. Ph.D Thesis University of Wisconsin-Madison, USA

Yo-Chan Son, Seung-Ki Sul (2002) A novel active common-mode EMI filter for PWM inverter. School of Electrical Engineering and Computer Science, \#24, ENG420, Seoul National Unviversity, Kwanak P. O. Box 34. Seoul, Korea (ZIP 151-742), http://eepel.snu.ac.kr, e-mail: sulsk@plaza.snu.ac.kr 